\title{
Individual Differences in Feedback Seeking: Counterintuitive Results Concerning Tolerance of Ambiguity
}

\author{
Gary Stark ${ }^{1}$ \\ ${ }^{1}$ College of Business, Northern Michigan University, Marquette, Michigan, USA \\ Correspondence: Gary Stark, College of Business, Northern Michigan University, Marquette, Michigan, 49855, USA. \\ Tel: 1-906-227-1244.
}

Received: December 31, 2015

Accepted: January 15, 2016

Online Published: March 7, 2016

doi:10.5430/ijba.v7n2p33

URL: http://dx.doi.org/10.5430/ijba.v7n2p33

\begin{abstract}
The purpose of this study was to replicate previous findings regarding the association between feedback seeking and the individual difference constructs of tolerance of ambiguity and locus of control, using unique measures of said individual differences. Namely, while previous feedback seeking research used Norton's (1975) tolerance of ambiguity measures, this study used Budner's (1962) measure to capture facets of tolerance of ambiguity not captured by Norton's measure. Locus of control was measured using Rotter's (1966) dispositional measure while previous feedback seeking research relied on experimentally creating conditions of perceived control. This study used a laboratory setting. Respondents, 137 undergraduates at a U.S. university, were told they were taking a management aptitude test and were measured as to their interest in feedback and feedback sought on said test. Feedback seeking was measured three different ways -- self-reported behavior, observed (by the researcher) behavior, and respondents' indication of intent to seek feedback. Contrary to expectations, tolerance of ambiguity was positively, rather than inversely, associated with feedback seeking. There was not a significant relation between locus of control and feedback seeking. Self-reported feedback seeking differed from observed feedback seeking.
\end{abstract}

Keywords: feedback seeking, locus of control, tolerance of ambiguity

\section{Introduction}

\subsection{Importance of Feedback Seeking}

Theory and practice point to the importance of feedback in improving task performance (e.g., Bandura, 1991; De Stobbeleir, Ashford, \& Buyens, 2011; Kluger \& DeNisi, 1996; Locke \& Latham, 1990). However, since the flow of feedback in organizations is often limited (Herold \& Parsons, 1985; Renn \& Fedor, 2001), individuals engage in feedback seeking behavior to gain much of the information needed to improve performance (Anseel, Beatty, Shen, Lievens, \& Sackett, 2015; Ashford, 1986; Ashford, Blatt, \& VandeWalle, 2003; Hays \& Williams, 2011). "Viewing feedback recipients as active participants in the feedback process... further highlights the need to understand the role of individual differences in shaping this process" (Linderbaum \& Levy, 2010, p. 1373). This study examined what effect individual differences in tolerance of ambiguity and locus of control have on performance feedback seeking.

\subsection{Tolerance of Ambiguity and Feedback Seeking}

Tolerance of ambiguity is the extent to which individuals perceive ambiguous situations as sources of threat (Budner, 1962). Research generally indicates those with a low tolerance of ambiguity regarding job performance may be motivated to reduce that ambiguity by seeking performance feedback (Bennett, Herold, \& Ashford, 1990). However, as will be detailed shortly, I suggest that a more appropriate measure of tolerance of ambiguity will help the field gain a greater understanding of this relationship.

Those studies that have investigated the tolerance of ambiguity-performance relationship directly have generally found tolerance of ambiguity to be inversely associated with feedback seeking. Bennett, et al. (1990) examined marketing employees at a public utility. Madzar (2001) surveyed engineers at a medical technology company. Both studies found lower levels of tolerance of ambiguity to be significantly related to higher levels of performance feedback seeking. Fedor, Rensvold, \& Adams (1992) studied U.S. Army helicopter pilot trainees on a multitude of factors expected to affect feedback seeking. They also found that, in general, tolerance of ambiguity was inversely related to performance feedback seeking. 
Results were slightly more complex in two other studies. Madzar (2005) found non-significant results for the tolerance of ambiguity - feedback seeking relationship with the exception of the French portion of her sample of employees of a large MNC. The French employees showed a counter-intuitive positive relationship between tolerance of ambiguity and feedback seeking. Madzar speculated (but did not test) that the results were related to the fact that the sample was from a MNC (which have unique cultures) and the fact that the French part of the sample were unusually low in tolerance of ambiguity. Cheramie (2014) surveyed medical and marketing employees and found that tolerance of ambiguity was negatively related to feedback seeking in public feedback seeking conditions but not in private.

The studies mentioned in this section of the paper (1.2), all examined the relationship between feedback seeking and tolerance of ambiguity using subscales of Norton's (1975) 50 item tolerance of ambiguity scale. Bennett, et al. (1990) used 3 of the 4 items from Norton's (1975) "job-related" tolerance of ambiguity subscale in finding a significant relationship between tolerance of ambiguity and performance feedback seeking. However, Bennett, et al. (1990) also examined the tolerance of ambiguity- feedback seeking relationship using 4 of the 9 items from Norton's "problem-solving" tolerance of ambiguity scale and found that problem-solving tolerance of ambiguity did not correlate significantly with performance feedback seeking. This suggests a need to examine the tolerance of ambiguity construct more closely when predicting feedback seeking behaviors.

While the Norton (1975) subscales were useful in demonstrating tolerance of ambiguity effects, they focus more on performance context (role and reward ambiguity) than on performance content (task ambiguity, evaluation ambiguity). Herold, Parsons, \& Rensvold (1996) called for further study of individual differences in the seeking and processing of actual performance feedback. Accordingly, this study seeks to broaden the findings cited in the previous paragraph by using a measure that may provide more focus on how tolerance of ambiguity relates to feedback seeking when knowledge of performance (e.g., level of achievement) is uncertain.

While there are several measures of tolerance of ambiguity in the extant literature, Budner's (1962) Intolerance of Ambiguity Scale is the most widely used (Furnham \& Ribchester, 1995; Furman \& Marks, 2013; Herman, Stevens, Bird, Mendenhall, \& Oddou, 2010). Budner's scale has been noted as being well grounded conceptually (Kirton, 1981 ) and is noted for its content, concurrent, and construct validity (Furnham \& Ribchester, 1995). Its wide use may allow easier comparisons to other studies involving tolerance of ambiguity, and its length (16 items versus Norton's 50 items) allows for ease of administration (Furnham \& Ribchester, 1995). As described above, prior studies have "gotten around" the length of Norton's (1975) instrument by using subscales. However, this has created potential reliability and comparison concerns (Herold, et al., 1996). Budner's (1962) scale considers task novelty, complexity, and insolubility (a situation characterized by conflicting cues) as sources of ambiguity. I felt these facets of Budner's scale help to more fully capture potential ambiguities of the task itself that might direct one to seek feedback about one's task performance. For example, one might be inclined to seek performance feedback in situations where multiple performance criteria exist (e.g. new sales vs. sales volume vs. repeat customers, etc.). In summary, I hypothesize, as have previous studies, that tolerance of ambiguity is inversely related to task performance feedback seeking. I suggest that the use of Budner's measure of the independent variable adds depth to this area of study.

\subsection{Locus of Control and Feedback Seeking}

Another individual difference that should relate to feedback seeking is locus of control. According to Rotter (1966), people maintain generalized self-expectancies regarding the amount of control they have over their reinforcers. Internals perceive outcomes to be contingent on their own actions (i.e., "I was the cause of my success or failure") while Externals typically attribute outcomes to forces beyond their own control, such as luck or an especially easy or especially difficult situation. Internals are also more likely to take responsibility for those things that happen in their environment (Blau, 1993). Rotter (1966) showed that Internals are more likely to be attentive to information in the environment, ask more questions, remember more information, and engage in more action to improve their environment. More recently, Internals have been found to be more effective leaders (Blau, 1993) and to be more active in managing their careers (Hammer \& Vardi, 1981). Linderbaum \& Levy (2010) suggest that Internals are high in Accountability and Feedback Self-Efficacy, which are two parts of the construct of Feedback Orientation.

These factors suggest Internals may take an active role in receiving and processing information from any source. Some have suggested Internals might be expected to seek task performance information to attempt to better themselves (Herold, et al., 1996; Lefcourt, 1982: 61). Relatedly, Renn \& Fedor (2001), and Trope, Gervey, \& Bolger (2003) found support for their hypotheses that perceived control leads to increased performance feedback seeking. Of note in both of these studies is that perceived control was experimentally manipulated and thus situational rather than dispositional. I propose these findings can be generalized to the dispositional level and thus that individuals with 
an internal locus of control will have a greater tendency to seek task performance feedback than those with an external locus of control.

\section{Method}

\subsection{Participants}

I recruited 137 undergraduates from management classes at a Midwestern U.S. university. Participants were offered extra credit in their classes for their participation, and were offered assignments other than this exercise by which to obtain the same amount of extra credit. The sample consisted of 53 women and $84 \mathrm{men}$. Of the 137 participants 72 were juniors and 54 were seniors; 107 were business majors. In contrast to traditional student samples, nearly all $(91 \%)$ of the participants had work experience (mean tenure $=5.8$ years) and the mean age was 22.0 years.

\subsection{Task \& Procedure}

Participants completed an adaptation of the Graduate Management Admissions Test (GMAT) which required that participants provide short written answers to questions regarding reading passages. The use of short answer questions was designed to make the test difficult to self-grade. Thus, participants had to rely on the researchers for feedback. Participants were informed that the test was a commonly used instrument to assess management aptitude. Comments gathered from participants afterwards indicated they clearly believed that they were being tested for their management aptitude. My use of a GMAT-style test is similar to that of Morrison \& Cummings (1992) in another feedback seeking study.

After taking the GMAT test and completing the personality measures and demographic information, the participants were told that they had an opportunity to obtain their scores by visiting the author's office in the two days following the test. I felt this procedure would better reflect actual organizational settings where one could expect a time lag between performance and feedback opportunity. Participants were asked to indicate on their test packets their intention to either seek or not seek feedback so the experimenters could prepare their feedback. Since the participants were all students in various management classes, this suggests that the research design had the important characteristics of a naturally occurring laboratory study. That is, since these participants were currently studying management and many had indicated a likelihood of pursuing a graduate management program, I believe that a test of their management aptitude, in essence, was a measure of their "job" performance.

\subsection{Measures}

\subsubsection{Tolerance of Ambiguity}

As previously discussed, this independent variable was measured using Budner's (1962) Intolerance of Ambiguity scale. This scale asks respondents to rate their level of agreement on a 1 (strongly disagree) to 7 (strongly agree) Likert scale to such statements as "An expert who doesn't come up with a definite answer probably doesn't know much". Higher scores indicate greater intolerance of ambiguity. In this study Cronbach alpha was .66.

\subsubsection{Locus of Control}

This construct was measured using Rotter's (1966) Locus of Control scale. This scale asks respondents to choose one between pairs of statements such as "Leaders are born, not made" and "Leaders are made, not born". There are 29 such pairs. The scale has shown acceptable psychometric properties and is the most well-known locus of control measure (Spector, 1982). Higher scores represent more externality. In this study Cronbach alpha was .66.

\subsubsection{Feedback Seeking}

I used three approaches to measuring feedback seeking. The first measure of feedback seeking asked participants to report their Feedback Seeking Intent (namely, to visit the author's office). This use of a behavioral "indicator" is consistent with a Trope \& Neter (1994) experiment that operationalized feedback seeking in a single item asking participants to rate their interest in receiving feedback.

As the second feedback seeking measure, I measured Observed Feedback Seeking Behavior. Similar to Morrison \& Cummings (1992), I recorded whether individuals came to my office to obtain feedback.

The third feedback seeking measure was Self-Reported Feedback Seeking Behavior. In the debriefing within a week of the original data collection I administered a questionnaire that included the question "did you ask for feedback on your (test) score?" Collected at three separate times, these three measures attenuate concerns about common method bias.

Each of the feedback seeking measures was a simple yes-no item, and thus two groups were formed for each measure: Feedback Seekers (coded as 1) and Feedback Non-seekers (coded as 2). 


\subsubsection{Control Variables}

To control for possible demographic effects (Knight \& Nadel, 1986, Tsui, Egan, \& O'Reilly, 1992), I requested age, gender, and college credit hours (a proxy for organizational tenure).

\section{Results}

Descriptive statistics and intercorrelations for the study variables are shown in Table 1. None of the demographic variables were significantly associated with the outcome variables.

Table 1. Means, standard deviations, and correlations ${ }^{\mathrm{a}}$

\begin{tabular}{|c|c|c|c|c|c|c|c|c|}
\hline Variables & Mean & 1 & 2 & 3 & 4 & 5 & 6 & 7 \\
\hline $\begin{array}{l}\text { 1. Feedback } \\
\text { Seeking Intent }\end{array}$ & $\begin{array}{l}42 \% \\
\text { yes }\end{array}$ & & & & & & & \\
\hline $\begin{array}{l}\text { 2. Observed } \\
\text { Feedback Seeking } \\
\text { Beh. }^{\text {b }}\end{array}$ & $\begin{array}{l}15 \% \\
\text { yes }\end{array}$ & $.17+$ & & & & & & \\
\hline $\begin{array}{l}\text { 3. Self-Report FB } \\
\text { Seeking Beh }^{\mathrm{b}}\end{array}$ & $\begin{array}{l}36 \% \\
\text { yes }\end{array}$ & $.81 * * *$ & $.47 * * *$ & & & & & \\
\hline 4. TA & $\begin{array}{l}3.55 \\
(.67)\end{array}$ & $-.21^{*}$ & -.12 & $-.25^{* *}$ & & & & \\
\hline 5. LOC & $\begin{array}{l}5.12 \\
(2.94)\end{array}$ & .00 & -.04 & .03 & $.19^{*}$ & & & \\
\hline 6. Age & $\begin{array}{l}22.0 \\
(4.70)\end{array}$ & -.03 & .08 & .11 & -.12 & .09 & & \\
\hline 7. Gender ${ }^{\mathrm{c}}$ & $\begin{array}{l}39 \% \\
\text { female }\end{array}$ & $-.17+$ & .06 & -.09 & .07 & -.06 & -.01 & \\
\hline 8. Credit Hours & $\begin{array}{l}78.36 \\
(24.62)\end{array}$ & -.09 & -11 & -.02 & $-.26^{* *}$ & -.06 & -.01 & $-.18+$ \\
\hline
\end{tabular}

${ }^{a}$ standard deviations in parentheses; $\mathrm{N}=137$

${ }^{\mathrm{b}}$ Dichotomous ( $0=$ no, $1=$ yes $)$

${ }^{\mathrm{c}}$ Dichotomous $(1=$ male, $2=$ female $)$

$+\mathrm{p}<.10$

$* \mathrm{p}<.05$

$* * \mathrm{p}<.01$

$* * * \mathrm{p}<.001$

\subsection{Tolerance of Ambiguity Results}

The first hypothesis stated that tolerance of ambiguity would be related to feedback seeking. Since the relationship between gender and feedback seeking intent was close to significance $(r=-.17, p<.06)$, as a conservative measure, I performed a hierarchical regression analysis to test the additional effect tolerance of ambiguity has on feedback seeking beyond any potential influence of gender. In addition, there has been some debate (cf. O'Brien, 1984) about the conceptual and empirical relationship between tolerance of ambiguity and locus of control. Since their 
interrelationship here was significant $(r=.19, \mathrm{p}<.05)$ I entered them into the regression equations together to test their potential mutual effects on feedback seeking. The results are shown in Table 2.

Tolerance of ambiguity was significantly and inversely related to Feedback Seeking Intent $(\exists=-.21, p<.05)$. This is opposite of what was predicted in the first hypothesis.

Tolerance of ambiguity was not significantly associated with the second measure of feedback seeking, observed feedback seeking behavior $(\exists=-.13$, ns).

Similar to results from the feedback seeking intent measure, tolerance of ambiguity was significantly associated with the third measure of feedback seeking, self-reported feedback seeking Behavior $(r=-.21, p<.01)$. Again, this is opposite of the prediction in hypothesis one.

It is important to reiterate that the results for tolerance of ambiguity were in the opposite direction to what I hypothesized. That is, I expected that individuals lower in tolerance of ambiguity would engage in more feedback seeking. Since Budner's (1962) scale is coded such that higher scores represent lower tolerance of ambiguity (stated differently, higher scores represent greater intolerance of ambiguity), and feedback seeking was coded as a higher number ("1") than feedback non-seeking ("0"), I expected positive correlations between the variables. Instead, I found negative correlations. Thus, my findings suggest that higher tolerance of ambiguity, not lower tolerance of ambiguity, leads to performance feedback seeking.

Table 2. Results of hierarchical regression ${ }^{\mathrm{a}}$

\begin{tabular}{cccll}
\hline Dependent & B & SE B & $\exists$ & t \\
\hline \multicolumn{2}{l}{ Feedback Seeking Intent } & & & $-1.97+$ \\
Step 1. Gender & -.17 & .09 & -.17 & $-1.8+$ \\
Step 2.Gender & -.15 & .08 & -.16 & $-2.39^{*}$ \\
TA & -.16 & .07 & -.21 & .38 \\
LOC & .03 & .02 & .03 & \\
Observed Feedback Seeking Behavior & & & .66 \\
Step 1. Gender & .07 & .11 & .06 & .70 \\
Step 2. Gender & .08 & .11 & .07 & -1.36 \\
TA & -.11 & .08 & -.13 & -.28 \\
LOC & -.01 & .02 & -.03 & -1.16 \\
Researcher-Reported Feedback Seeking Behavior & & .1 .0 \\
Step 1. Gender & -.11 & .09 & -.11 & $-3.07 * *$ \\
Step 2. Gender & -.09 & .09 & -.09 & .42 \\
TA & -.21 & .07 & -.29 & .04 \\
LOC & .01 & .02 & &
\end{tabular}

a df Step 1=1,126; Step 2=3, 124

$+\mathrm{p}<.10$

* $\mathrm{p}<.05$

$* * \mathrm{p}<.01$

\subsection{Locus of Control Results}

The second hypothesis predicted that internal locus of control would be related to greater feedback seeking. Table 1 shows no significant relationship between locus of control and feedback seeking intent $(\mathrm{r}=.00$, ns), observed feedback seeking behavior $(\mathrm{r}=-.04, \mathrm{~ns})$, nor self-reported feedback seeking behavior $(\mathrm{r}=.03, \mathrm{~ns})$. Thus, hypothesis two is not supported. 


\section{Discussion}

This study sought to replicate previous studies while using a different tolerance of ambiguity measure, a standard locus of control inventory (as opposed to manipulated locus of control conditions), and a controlled laboratory design. The results of this study were different from what was predicted. I predicted that feedback seeking would be characteristic of individuals who are intolerant of ambiguity and individuals with an internal locus. Instead, the results showed that those who were more tolerant of ambiguity intended to seek (and reported seeking) performance feedback while those less tolerant of ambiguity did not intend to seek (or report seeking) feedback. The results also showed no significant relationship between locus of control and feedback seeking.

\subsection{Explanations for Tolerance of Ambiguity Results}

\subsubsection{Ambiguity of Feedback}

One possible explanation for the findings regarding tolerance of ambiguity is that feedback may in fact make some situations more ambiguous (Ashford \& Cummings 1983: 391), therefore prompting low tolerance of ambiguity individuals to avoid feedback. As an interpersonal process, feedback seeking requires that the feedback seeker weigh various motives or agendas of the giver (e.g., impression management, ego boosting, and so on) in judging the accuracy of the feedback (p. 391). Similar to the present study, Gupta, Govindarajan, \& Malhotra (1999) found that executives with high role ambiguity engaged in less feedback seeking. Gupta, et al suggested (but did not test) that the reason for this relationship was that the task of interpreting feedback may add additional ambiguity. The potential complexity of feedback represented in this example may be captured by the "complexity" facet of Budner's measure. Budner's (1962) "novelty" component may be captured in a situation where performance feedback presents the seeker with the need or potential for new performance strategies or opportunities in light of the performance information (Earley, Connolly, \& Ekegren, 1989; Mone \& Baker, 1989). Work by Fedor and his associates (e.g. Fedor 1990; Fedor, et al., 1992) demonstrated that in some situations performance feedback can raise uncertainties because it conflicts with previously held beliefs about one's performance level. This potential "insolubility" created by feedback reflects the third facet of Budner's (1962) scale. Future research should more closely examine ways in which feedback may create ambiguity and thus the situations which may inhibit individuals from seeking performance feedback.

Related to the previous paragraph, the counterintuitive findings might be explained by evidence that individuals with low tolerance of ambiguity may not have the desire to acquire and integrate the information presented by performance feedback, and thus may avoid it (Raju, 1980; Sorrentino, Hewitt, \& Raso-Knott, 1992). This potential explanation rests more on the nature of tolerance of ambiguity than on the complexity of feedback. McLain (1993) defined tolerance of ambiguity in terms of rejection of information subject to multiple interpretations. Thus, it appears that low tolerance of ambiguity individuals may avoid some information because it opens the door to further ambiguities. Low tolerance of ambiguity individuals may over-simplify reality in order to remain more cognitively certain. Future research should examine the possibility that there are situations where those with low tolerance of ambiguity may maintain a simpler cognitive schema by avoiding feedback. Recall that Bennett, et al. (1990) found the hypothesized relationship of low tolerance of ambiguity to higher feedback seeking. However, if one breaks down the tolerance of ambiguity measures in the Bennett, et al. (1990) study it is interesting to note that individuals high in problem-solving tolerance of ambiguity rather than those low in problem solving tolerance of ambiguity who were found to solicit their supervisors most often for information about their promotion potential. Similarly, in the Fedor, et al. (1992) study, high tolerance of ambiguity helicopter pilots in the basic instrument phase of pretraining monitored the environment for feedback more than low tolerance of ambiguity individuals. Both of these findings, though not the focus of their studies, reflect the same counterintuitive results I discovered. These situations may both be conceived of as cognitively complex, suggesting that individuals low in tolerance of ambiguity may have avoided feedback because of its cognitive complexity.

\subsubsection{Motives for Feedback Seeking}

Another possible explanation for the counterintuitive findings is that those individuals who intended to seek feedback were motivated by something other than a simple assessment of their performance. Research suggests that there are many possible motives for seeking feedback. Most commonly discussed are self-assessment, self-enhancement and self-verification (Anseel, et al., 2015; Sedikides, 1993). While all of these motives produce searches for information, self-verification and self-enhancement do not activate searches for the purpose of performance assessment. Instead self-verification and self-enhancement provide information useful for producing or maintaining self-image or social status, of which task performance may be one aspect. If the participants in the study were pursuing motives other than self-assessment, then feedback sought might not be sought for purposes of decreasing ambiguity, but rather for 
purposes of maintaining or producing their individual images. Future research should examine how feedback seeking motives moderate the tolerance of ambiguity- feedback seeking relationship.

\subsection{Locus of Control Results}

The hypothesis that locus of control would be associated with feedback seeking was not supported. One reason for these results may be range restriction in the locus of control data in this study. The maximum possible score on this scale is 23 , representing an extremely external locus. The minimum possible score is 0 , representing an extremely internal locus. In this sample 83.5 percent of the participants scored 8 or below. For comparison purposes, Rothberg (1980) indicated that the mean score was 8.29 for both corporate business executives and elite career military officers, both of which are reported to display strong internal locus of control. The mean for the sample was 5.39. Clearly then, there was not enough variance in locus of control scores to be useful in predicting feedback seeking. Of the locus of control-related studies cited earlier, Trope, Gervey, \& Bolger (2003) manipulated a sufficient variance through experimental conditions. Renn \& Fedor (2001) examined perceived control as a contextual variable and this may have caused more natural variance. Future research should sample populations where a wider range of locus of control could be expected.

\subsection{Differences in Feedback Seeking Results}

While I found significant results for Feedback Seeking Intent and for Self-Reported Feedback Seeking Behavior, the results for Observed Feedback Seeking Behavior were not significant. It is worth examining why so few (15) of the participants who stated their intent to do so (57) actually did report to the author's office to receive feedback.

Past research (Cheramie, 2014; Levy, Albright, Cawley, \& Williams, 1995; Northcraft \& Ashford, 1990) has shown that feedback seeking requests decrease as the request setting is more public. To reduce this "public" effect and to promote anonymity, I used a pencil-and-paper feedback seeking intent form that all participants completed. This procedure is similar to Northcraft \& Ashford's (1990) private request condition and stands in contrast to the use of brightly colored request forms in their public condition. Levy, et al. (1995) also offered evidence that public feedback request conditions caused participants to reconsider their initial intent to seek feedback. In that study, many public condition participants who had intended to seek feedback did not actually request feedback. While I used student-initiated office visits to promote a confidential setting, the Levy, et al. (1995) study suggests that if many of my participants considered a visit to the experimenter's office a highly visible act (I suggest that this is plausible), it could have inhibited feedback seeking intent from becoming feedback seeking behavior. Cheramie (2014) found that tolerance of ambiguity had a negative relationship with feedback seeking in public feedback seeking settings but that the relationship was positive (as in the current study) in private. Further research should take care to establish the context (public versus private) of feedback seeking.

A final note for future research concerns the discrepancy between self-reported and observed feedback seeking. There were 57 participants who indicated their intent to seek feedback and many of them (the 43 who self-reported that they sought feedback) may have thought that by indicating intent they were actually asking for feedback. Indeed, the correlation between Feedback Seeking Intent measure and Self-Reported Feedback Seeking Behavior was .81 $(\mathrm{p}<.001)$. This explanation seems peculiar though since there was no indication at the testing session that I would be revisiting the participants' classes and I made it clear that to get performance feedback the participants would have to visit my office. Thus, in indicating that they intended to seek feedback, the participants should not have thought that it was to be delivered to them without them making further effort.

At issue then is what people perceive as "asking for feedback" and, hence, how they report feedback seeking behavior. The majority of the field research done on feedback seeking behavior relies on self reports. Given the discrepancy between self-reported and actual behavior found in this study though, there should be some concern (beyond traditional common method issues) as to the accuracy of self-reported feedback seeking behavior. In this study the discrepancies were in the definition of feedback seeking behavior that occurred within the preceding week (checking a box on a form vs. visiting a specified office). Field surveys are typically designed to measure behavior for much longer periods and thus may be cause for additional concern. Future research should be directed toward understanding organization members' perceptions of what they consider feedback seeking behavior and towards the development of accurate and replicable measures of feedback seeking behavior (e.g. Ashford \& Tsui, 1991).

While this study provides some extensions concerning feedback seeking, performance, and tolerance of ambiguity, it also points to many issues for future research. 


\section{References}

Anseel, F., Beatty, A.S., Shen, W., Lievens, F., \& Sackett, P. R. (2015). How are we doing after 30 years? A meta-analytic review of the antecedents and outcomes of feedback-seeking behavior. Journal of Management, 41, 318-348. http://dx.doi.org/10.1177/0149206313484521

Ashford, S. J. (1986). Feedback seeking in individual adaptation: A resource perspective. Academy of Management Journal, 29, 465-487. http://dx.doi.org/10.2307/256219

Ashford, S. J., \& Cummings, L. L. (1983). Feedback as an individual resource: Personal strategies of creating information. Organizational Behavior and Human Decision Processes, 32, 370-398. http://dx.doi.org/10.1016/0030-5073(83)90156-3

Ashford, S. J., \& Tsui, A. S. (1991). Self-regulation for managerial effectiveness: The role of active feedback seeking. Academy of Management Journal, 34, 251-280. http://dx.doi.org/10.2307/256442

Ashford, S. J., Blatt, R., \& VandeWalle, D. (2003). Reflections on the looking glass: A review of research on feedback-seeking behavior in organizations. Journal of Management, 29, 773-799. http://dx.doi.org/10.1016/S0149-2063_03_00079-5

Bandura, A. (1991). Social cognitive theory of self regulation. Organizational Behavior and Human Decision Processes, 50, 248-287. http://dx.doi.org/10.1016/0749-5978(91)90022-L

Bennett, N., Herold, D. M., \& Ashford, S. J. (1990). The effects of tolerance for ambiguity on feedback seeking $\begin{array}{llll}\text { behavior. Journal of } & \text { Occupational }\end{array}$ http://dx.doi.org/10.1111/j.2044-8325.1990.tb00535.x

Blau, G. (1993). Testing the relationship of locus of control to different performance dimensions. Journal of $\begin{array}{lllll}\text { Occupational and } & \text { Organizational }\end{array}$ http://dx.doi.org/10.1111/j.2044-8325.1993.tb00522.x

Budner, S. (1962). Intolerance of ambiguity as a personality variable. Journal of Personality, 30, 29-50. http://dx.doi.org/10.1111/j.1467-6494.1962.tb02303.x

Cheramie, R. A. (2014). Predicting public or private feedback-seeking behaviors. American Journal of Business, 29, 261-275. http://dx.doi.org/10.1108/AJB-02-2014-0013

De Stobbeleir, K. E. M., Ashford, S. J., \& Buyens, D. (2011). Self-regulation of creativity at work: The role of feedback-seeking behavior in creative performance. Academy of Management Journal, 54, 811-831. http://dx.doi.org/10.5465/AMJ.2011.64870144

Earley, P. C., Connolly, T., \& Ekegren, G. (1989). Goals, strategy development, and task performance: Some limits on the efficacy of goal setting. Journal of Applied Psychology, 74, 24-33. http://dx.doi.org/10.1037/0021-9010.74.1.24

Fedor, D. B. (1990). Feedback recipients' responses to negative feedback: Investigating the role of uncertainty. Paper presented at the annual meeting of the Society for Industrial and Organizational Psychology, Miami Beach, FL.

Fedor, D. B., Rensvold, R. B., \& Adams, S. M. (1992). An investigation of factors expected to affect feedback seeking: A longitudinal field study. Personnel Psychology, 45, 779-805. http://dx.doi.org/10.1111/j.1744-6570.1992.tb00968.x

Furnham, A., \& Marks, J. (2013). Tolerance of ambiguity: A review of the recent literature. Psychology, 4, 717-728. http://dx.doi.org/10.4236/psych.2013.49102

Furnham, A., \& Ribchester, T. (1995). Tolerance of ambiguity: A review of the concept, its measurement and applications. Current Psychology: Developmental, Learning, Personality, 14, 179-199. http://dx.doi.org/10.1007/BF02686907

Gupta, A. K., Govindarajan, V., \& Malhotra, A. (1999). Feedback-seeking behavior within multinational $\begin{array}{llll}\text { corporations. } & \text { Strategic } & \text { Management } & \text { Journal, }\end{array}$ http://dx.doi.org/10.1002/(SICI)1097-0266(199903)20:3<205::AID-SMJ17>3.0.CO;2-H

Hammer, T. H., \& Vardi, Y. (1981). Locus of control and career self-management among non-supervisory employees in industrial settings. Journal of Vocational Behavior, 18, 13-29. http://dx.doi.org/10.1016/0001-8791(81)90026-9 
Hays, J. C., \& Williams, J. R. (2011). Testing multiple motives in feedback seeking: The interaction of instrumentality and self protection motives. Journal of Vocational Behavior, 79, 496-504. http://dx.doi.org/10.1016/j.jvb.2011.01.007

Herman, J. L., Stevens, M. J., Bird, A., Mendenhall, M., Oddou, G. (2010). The Tolerance for Ambiguity Scale: Towards a more refined measure for international management research. International Journal of Intercultural Relations, 34, 58-65. http://dx.doi.org/10.1016/j.ijintrel.2009.09.004

Herold, D. M., \& Parsons, C. K. (1985). Assessing the feedback environment in work organizations: Development of the job feedback survey. Journal of Applied Psychology, 70, 209-305. http://dx.doi.org/10.1037/0021-9010.70.2.290

Herold, D. M., Parsons, C. K., \& Rensvold, R. B. (1996). Individual differences in the generation and processing of performance feedback. Educational and Psychological Measurement, 56, 5-25. http://dx.doi.org/10.1177/0013164496056001001

Kirton, M. J. (1981). A reanalysis of two scales of tolerance of ambiguity. Journal of Personality Assessment, 45, 407-414. http://dx.doi.org/10.1207/s15327752jpa4504_10

Kluger, A. N., \& DeNisi, A. (1996). The effects of feedback interventions on performance: A historical review, a meta-analysis, and a preliminary feedback intervention theory. Psychological Bulletin, 119, 254-284. http://dx.doi.org/10.1037/0033-2909.119.2.254

Knight, P. A., \& Nadel, J. I. (1986). Humility revisited: Self-esteem, information search, and policy consistency. Organizational Behavior and Human Decision Processes, 38, 196-206. http://dx.doi.org/10.1016/0749-5978(86)90016-6

Lefcourt, H. M. (1982). Locus of control: Current trends in theory and research (2 ${ }^{\text {nd }}$ ed.). Hillsdale, NJ: Erlbaum.

Levy, P. E., Albright, M. D., Cawley, B. D., \& Williams, J. R. (1995). Situational and individual determinants of feedback seeking: A closer look at the process. Organizational Behavior and Human Decision Processes, 62, 23-37. http://dx.doi.org/10.1006/obhd.1995.1028

Linderbaum, B. A., \& Levy, P. E. (2010). The development and validation of the feedback orientation scale (FOS). Journal of Management, 36, 1372-1405. http://dx.doi.org/10.1177/0149206310373145

Locke, E. A., \& Latham, G. P. (1990). A theory of goal setting and task performance. Englewood Cliffs, NJ: Prentice Hall.

Madzar, S. (2001). Subordinates information inquiry: Exploring the effect of perceived leadership style and individual differences. Journal of Occupational and Organizational Psychology, 74, 221-232. http://dx.doi.org/10.1348/096317901167325

Madzar, S. (2005). Subordinates' information inquiry in uncertain times: A cross cultural consideration of leadership style effect. International Journal of Cross Cultural Management, 5, 255-274. http://dx.doi.org/10.1177/1470595805058412

McLain, D. L. (1993). The MSTAT-I: A new measure of an individual's tolerance for ambiguity. Educational and Psychological Measurement, 53, 183-189. http://dx.doi.org/10.1177/0013164493053001020

Mone, M. A., \& Baker, D. B. (1989). Stage of task learning as a moderator of the goal-performance relationship. Human Performance, 2, 85-99. http://dx.doi.org/10.1207/s15327043hup0202_1

Morrison, E. W., \& Cummings, L. L. (1992). The impact of feedback diagnosticity and performance expectations on feedback seeking behavior. Human Performance, 5, 251-264. http://dx.doi.org/10.1207/s15327043hup0504_1

Northcraft, G. B., \& Ashford, S. J. (1990). The preservation of self in everyday life: The effects of performance expectations and feedback context on feedback inquiry. Organizational Behavior and Human Decision Processes, 47, 42-64. http://dx.doi.org/10.1016/0749-5978(90)90046-C

Norton, R. W. (1975). Measurement of ambiguity tolerance. Journal of Personality Assessment, 39, 607-619. http://dx.doi.org/10.1207/s15327752jpa3906_11

O’Brien, G. E. (1984). Locus of control, work, and retirement. In H.M. Lefcourt (Ed.), Research with the locus of control construct (pp. 7-72). Orlando: Academic Press. http://dx.doi.org/10.1016/b978-0-12-443203-1.50006-5

Raju, P. S. (1980). Optimum stimulation level: Its relationship to personality, demographics, and exploratory behavior. Journal of Consumer Research, 7, 272-282. http://dx.doi.org/10.1086/208815 
Renn, R. W., \& Fedor, D. B. (2001). Development and field test of a feedback seeking, self-efficacy, and goal setting model of work performance. Journal of Management, 27, 563-572. http://dx.doi.org/10.1177/014920630102700504

Rothberg, D. L. (1980). Professional achievement and locus of control: A tenuous inference reconsidered. Psychological Reports, 46, 183-188. http://dx.doi.org/10.2466/pr0.1980.46.1.183

Rotter, J. B. (1966). Generalized expectancies for internal versus external control of reinforcement. Psychological Monographs, 80 (Whole No. 609). http://dx.doi.org/10.1037/h0092976

Sedikides, C. (1993). Assessment, enhancement, and verification determinants of the self-evaluation process. Journal of Personality and Social Psychology, 65, 317-338. http://dx.doi.org/10.1037/0022-3514.65.2.317

Sorrentino, R. M., Hewitt, E. C., \& Raso-Knott, P. A. (1992). Risk-taking in games of chance and skill: Informational and affective influences on choice behavior. Journal of Personality and Social Psychology, 62, 522-533. http://dx.doi.org/10.1037/0022-3514.62.3.522

Spector, P. E. (1982). Behavior in organizations as a function of employee's locus of control. Psychological Bulletin, 91, 482-497. http://dx.doi.org/10.1037/0033-2909.91.3.482

Trope, Y., \& Neter, E. (1994). Reconciling competing motives in self-evaluation: the role of self-control in feedback seeking. Journal of Personality and Social Psychology, 66, 646-657. http://dx.doi.org/10.1037/0022-3514.66.4.646

Trope, Y., Gervey, B., \& Bolger, N. (2003). The role of perceived control in overcoming defensive self-evaluation. Journal of Experimental Social Psychology, 39, 407-419. http://dx.doi.org/10.1016/S0022-1031(03)00035-0

Tsui, A. S., Egan, T. D., \& O’Reilly, C. A. (1992). Being different: Relational demography and organizational attachment. Administrative Science Quarterly, 37, 549-579. http://dx.doi.org/10.2307/2393472 